\title{
Children Medication Safety strategies: Its effect on Reducing Medication Errors among Pediatric Nurses Nagwa A. Zein Eldin ${ }^{1}$, Omayma M. Okby ${ }^{2}$, Fatma A. Abd Elrazek ${ }^{3}$, Samer F. Badawy ${ }^{4}$
}

\author{
${ }^{12}$ Professor of pediatric Nursing, Faculty of Nursing, Menoufia University \\ ${ }^{3}$ Lecturer of Pediatric Nursing, Faculty of Nursing, Menoufia University \\ ${ }^{4}$ BSC of Pediatric Nursing ${ }^{4}$ Faculty of Nursing, Menoufia University
}

\begin{abstract}
Medication safety means freedom from preventable harm associated with medication. Medication errors are considered the most common gap in safety that occurs in hospital settings, which, increase children mortality rate. For this reason. The purpose of this study was to evaluate the effect of children medication Safety strategies on medication errors among pediatric nurses. The design of this study was quasi experimental design. The setting: the study was conducted at the Pediatric Department in Menoufia University Hospital and Shebin El-kom Teaching Hospital. Sampling: A convenient samples of 50 nurses were obtained from the previous mentioned settings. Instruments: Three instruments were used; Instrument one contained structured interview questionnaire sheet was utilized to identify nurses' knowledge about medication administration safety. Instrument two was an observation checklist to observe nurses preparation for medication administration and detecting medication errors. Instrument three includes medication safety audit list for nurses. The results of this study showed that errors in the administration of medication occurred between $2 \%$ of nurses post intervention instead of $14 \%$ pre intervention, Also there were significant improvement in nurses' knowledge for medication safety on posttest and follow-up tests $(13.64 \pm 2.09)$ and $(12.58 \pm 1.6)$ respectively than on pretest $(8.02 \pm 3.7)$. Also, nurse's practices were improved after the implementation of safety strategies related to medication administration. Conclusions, implementation of safety strategies reduced medication errors and improved nurses' knowledge as well as practices regarding medication administration safety. Recommendation: applying medication Safety strategies to all pediatric units to improve nurses' knowledge and practices regarding medication safety.

Keywords: Safety strategies, Medication errors, Pediatric nurses
\end{abstract}

\section{Introduction}

Medication errors (MEs) are $18 \%$ of total medical errors, and are considered as one of the top ten causes of deaths in USA ,there is 7000 to 9000 death each years (Rayhan \&Yevgeniya , 2019: Bonney, 2013). In Egypt medication errors are $10.5 \%$ in pediatric neonates (El-Shazly, AlAzzouny, Solima, Abed \& Attia , 2017).

The children are particularly at greater risk for medication errors, the risk remains high, despite of interventions and changes of medical and healthcare system. Stockwell et al, (2018). Children safety is one of the major health concerns worldwide. Medical errors are one of the main factors affecting children safety and the quality of hospital services (Mrayyan, 2012). One of the most common types of medical services problems was medication administration errors (MEs), accounting for $10 \%-18 \%$ of total medical errors, medication errors are considered as one of the top ten causes of deaths throughout the world (Choi et al., 2016\& Bonney, 2013). The National Coordinating Council for 


\section{Children Medication Safety strategies: Its effect on Reducing Medication Errors among Pediatric Nurses}

Medical Error Reporting and Prevention National Coordinating Council for Medication Errors Reporting and Prevention: NCCMERP ( 2015) defined medication errors as: "any preventable event that may cause or lead to inappropriate medication use or patient harm while the medication is in the control of the healthcare professional ".

It is difficult to acquire accurate estimates about medication errors, but experts observed that the rate of these errors is high, and increasing number of complaints against health care team (Mohammad, Hojjati, Sharifniya \& Ehsani , 2012). It was estimated that these errors occur in the united States by 1.5 million times in-hospital occurrences, making it one of most common sources of preventable harm (Murray, Wolcott, Bootman \& Cronenwett, 2010). Also, every eight minutes children may receive wrong medication or wrong dosage and nearly 700,000 children under 6 years old experienced medication error between 2002 and 2012 and one out of four children was under a year old (Haelle \& Willingham, 2016).

Medication errors can occur in any phase of the medication process, including prescribing, dispensing, transcription, and administration. However, the majority of this errors are generally occur in the administration phase (Murray et al., 2010). Although medication errors can be caused by all health care professionals, they are more prevalent among nurses because they play a major role in the administration phase of the medication process (Schmidt \& Bottoni ,2013).
According to American Academy of pediatrics AAP, (2012) children medication safety can be ensure by stay current and knowledgeable concerning changes in medications and treatment of pediatric conditions. In addition, following guideline and strategies tips for medication prescribing, dispensing, transcription, and administration.

According to American Academy of Pediatrics , (2012) \& Vickerie (2017) strategies for pediatric medication safety are: Ensure the rights of medication administration follow proper medication procedures double check, consider using a name alert, dosage calculation sheets for critical care, place a zero in front of the decimal point, document everything, ensure proper storage of medications ,follow institution's medication administration policies ,follow regulations and guidelines as well as consider having a drug guide available at all times and ensure bar-coding technology .

Nurses spend approximately $40 \%$ of their time of nursing care in medication preparation and administration; so, it is important for all nurses to follow safety strategies to reduce and prevent medication errors and ensure correct administration of drugs as legal issues and address causes of medication errors (World Health Organization, 2017). Nurses play an important role in promoting children safety, because they are predominantly provide health care and administer medications. So, they must ensure that children receive the right medication, right dose, right route, right time and right evaluation for therapeutic and possible adverse events (World Health Organization, 2016: Choi, et al., 2016). So the purpose of the study was to evaluate the effect of 


\section{Children Medication Safety strategies: Its effect on Reducing Medication Errors among Pediatric Nurses}

medication safety strategies on reduction of medication errors among pediatric nurses.

\section{Purpose}

The purpose of this study was to evaluate the Effect of children medication safety strategies on reduction of medication errors among pediatric nurses.

\section{Research hypothesis}

Pediatric nurses who followed children medication safety strategies will have fewer medication errors on posttest than pretest.

\section{Operational definitions}

Medication safety strategies: it is strategies used to ensure medication safety by following strategies tips for medication by ensure medication right, prescribing, preparation, storage and administration (AAP, 2012).

Medication errors: A medication error is any preventable event that occurs in the process of delivering of the medication, regardless of occurrence of injury or the potential for injury was present (Joint Commission on Accreditation of Healthcare Organizations, 2002).

\section{Methods}

1-Design: A quasi-experimental research design was utilized for this study (pre and posttest).

2- Research setting: This study was conducted at the pediatric department in Menoufia University Hospital and Shebin El-kom Teaching Hospital.

3- Sampling: A convenient sample of 50 nurses was obtained from the previous mentioned settings (35 nurses from the pediatric ward of Menoufia University Hospital and 15 nurses from the pediatric ward at Shebin El_kom Teaching Hospital)

\section{Instruments}

Three instruments were utilized for data collection.

Instrument one: Structured Interview Questionnaire Sheet. It was designed by the researcher after reviewing related literature. This instrument was divided into two parts:

- Part one: Biosocial characteristic of studied nurses. It included questions about age, level of education and duration of experience in pediatric department.

- Part two: Structured questionnaire: to identify nurses' knowledge about medication administration safety, it contains 28 questions about causes of medication errors and strategies for prevention of these errors Scoring system for this questionnaire:

\begin{tabular}{|l|l|}
\hline Do not know & 0 \\
\hline Incomplete knowledge & 1 \\
\hline Complete knowledge & 2 \\
\hline
\end{tabular}

Instrument two: Observational checklist. It was developed by Härkänen, Turunen, Saano, \& Vehviläinen. (2013), to observe nurses practices during medication preparation, administration of medication It included 39 statements about nurses' general condition, distractions \& interruptions during drug administration, staff cooperation, medication record review, drug preparation, drug administration, stages of errors and severity of errors. There were to responses for each statement done or not done. Scoring system for each statement:-

\begin{tabular}{|l|r|}
\hline Not done & 0 \\
\hline Done & 1 \\
\hline
\end{tabular}

Instrument three:- Medication Safety Audit List for Nurses (MSALN): It was developed by the 


\section{Children Medication Safety strategies: Its effect on Reducing Medication Errors among Pediatric Nurses}

Ministry of Health in Singapore, (2009) and was modified by the researcher. It included 12 statements which related to Communication of drug orders, drug labeling and packing statements, drug storage, medication delivery and monitoring, environmental factors, staff competency, quality process and risk management. Scoring system for each observation:-

\begin{tabular}{|l|l|}
\hline Not done & 0 \\
\hline Done & 1 \\
\hline
\end{tabular}

\section{Validity}

For validity assurance, instruments were provided to a jury including one professor of pediatric nursing, two assistant professors of pediatric nursing and two assistant professors in pediatrics .The modifications was done to ascertain their relevance and completeness.

\section{Reliability}

The reliability of the instruments 1 was done to determine the extent to which items in the questionnaire were related to each other by Cranach's coefficiency alpha for the questionnaire $(\mathrm{a}=0.97)$. Pearson correlation coefficiency was used to test the internal consistency $(r=0.02-0.98)$ for all items of the questionnaire.

\section{Ethical consideration}

- An approval of the faculty of nursing institution research committee was obtained.

- A written formal consent for acceptance was obtained from the nurses.

- An initial interview was done to inform nurses about the purpose of the study and explain that participation in the study was voluntary and the participants could withdraw from the study at any time.

\section{Pilot study}

It was conducted on 5 nurses to test the applicability of the instruments to detect the obstacles and problem that may be encountered during data collection. It also helped to estimate the time needed to fill in the instrument; the pilot sample was excluded from the total sample.

\section{Procedure}

A formal letter was directed from the Dean of the faculty of Nursing, Menoufia University to the directors of Menoufia University hospitals and Shebin El-kom Teaching Hospital. Explaining the purpose data collection method.

Data collection for this study was conducted for a period of 8 months extending from the $1^{\text {st }}$ of October 2017 to the end of June 2018.

The researcher introduced herself to the nurses who shared in the study, explained the purpose of the study and methods of data collection.

Instrument one was distributed between nurses (pretest). Each data collection interview lasted between 20 to 30 minutes. It took about 4 weeks for all nurses to fulfill the pretest instrument.

The Structured Observation checklist form to observe nurse's preparation and administration of medication and detecting medication errors was done by the researcher by using instrument two (pretest).

Nurses were divided into small groups. Each group included about 3 to5 nurses. They received about 10 sessions within 4 weeks (2-3 sessions per week) .Each session lasted for 30 


\section{Children Medication Safety strategies: Its effect on Reducing Medication Errors among Pediatric Nurses}

minutes. Oral presentations, group discussions, feedbacks were used for health education and explanatory medication safety strategies were distributed between nurses. All sessions were conducted in the nursing room in the previously mentioned settings.

- The first session included information about medication safety and medication errors such as definitions of medication safety and medication errors, causes of medication errors, types of errors, causes of not reporting errors. Advantages, disadvantages and complications of oral, IM, IV, and SC medications for children.

- The second session included Strategies of medication safety It contained the following items: Ensure the rights of medication administration Follow proper medication procedures for children, double check by two nurses, consider using a name alert, Place a zero in front of the decimal point, document everything, ensure proper storage of medications for proper efficacy, Follow institution's medication administration policies for regulations, and guidelines, consider having a drug guide available at all times for every children categories Vickerie (2017).

- The third and The fourth session were conducted to train nurses about children medication safety and techniques of safety medication administration: topical medication administration (liquid, otic , ophthalmic and nasal medication administration, Techniques of safety medication administration as: IM, IV, ID and SC medication administration for children.
- The researcher taught nurses techniques of safety medication administration, by using dolls, group discussion, feedback, demonstration and re demonstration.

- At the end of sessions nurses were asked to rephrase their understanding about what they learned about medication safety, medication errors and techniques of safety medication administration. Misinformation and malpractice were corrected immediately and summary was provided.

- Immediate posttest and follow up test after six months were done by using the previous instruments used at pretest.

\section{Data analysis}

Data was analyzed by using SPSS (Statistical Package for Social Science) statistical package version 22. Quantitative data was expressed as mean \& standard deviation $(\mathrm{X} \pm \mathrm{SD})$ and analyzed by using Friedman test and ANOVA test for comparison between means. Qualitative data was expressed in the form of number and percentage. It was analyzed by using chi-square test (x2). Pearson correlation was used for explaining relationship between normally distributed quantitative variable. A statistical significant difference was considered if $\mathrm{p}<0.05$. A highly statistical significant difference was considered if $\mathrm{p}<0.001$.

\section{Results}

Table 1: Showed characteristics of studied nurses. It represented that half of studied nurses $(50 \%)$ were $>30$ years. their years of experience revealed that more than half of studied nurses (60\%) had >5 years of experience. All of studied nurses did 


\section{Children Medication Safety strategies: Its effect on Reducing Medication Errors among Pediatric Nurses}

not attend any previous training courses for medication safety

Figure 1: Showed nurses' knowledge about safety medication administration rights on pre, post and follow-up it showed that $18 \%$ of nurses did not have knowledge about safety medication administration rights on pretest compared to $72 \%$ and $66 \%$ of nurses who had complete knowledge on post and follow up tests respectively

Figure2: Distribution of nurses according to conducting errors in preparation, administration and documentations of medications on pre, post and follow- up test. It showed that the medication errors were conducted in preparation, administration and documentation at pre intervention by $24 \%, 28 \%$ and $14 \%$ of nurses, on post test, only $16 \%$ and $6 \%$ of nurses conducted errors in in documentation and administration.

Table 2: Represented Mean scores of nurses' total knowledge about medication errors and different medication route on pre, post and follow-up tests. It showed that nurses had higher scores of correct knowledge about medication safety on posttest (13.64 \pm 2.09$)$ and follow- up test $(12.58 \pm 1.6)$ than pretest $(8.02 \pm 3.7)$. It also, showed that nurses had higher scores of total knowledge on posttest (36.98 \pm 4.2$)$ and follow- up test (35.72 $\pm 2.00)$ than pretest $(24.84 \pm 6.7)$.For this reason, there were highly statistical significant differences between nurses 'knowledge at $0.001 \%$ level of statistical significance.

Table 3: Represented Means scores of total nurses' practices of safety preparation and administration of medication on pre, post and follow-up. It showed that the total medication observation form was high in posttest $(16.80 \pm 1.7)$ than follow up test (14.82 $\pm 0.96)$ and pretest $(14.84 \pm 1.4)$

Table 4: Represented the total means of medication safety audit list on pre, post and follow-up test. It showed that the mean score of medication safety audit list was high on posttest $(9.1 \pm$ $0.71)$ and follow-up test $(8.1 \pm 0.86)$ than on pretest (6.64 \pm 0.67$)$. Therefore, there were highly statistical significant differences $0.001 \%$ level of statistical significance.

Table 5: Illustrated Pearson correlation between total knowledge score and total medication observation score. There was a positive correlation between the total knowledge and total medication observation form at $0.001 \%$ level of statistical significance.

Figure 3: Represented Pearson Correlation between total knowledge and total medication observation form.

It illustrated that there was a positive correlation between total knowledge and total medication observation form at $0.001 \%$ level of statistical significance

Table (1): Characteristics of studied nurses 
Children Medication Safety strategies: Its effect on Reducing Medication Errors among Pediatric Nurses

\section{Nurses' knowledge about safety medication administration rights}

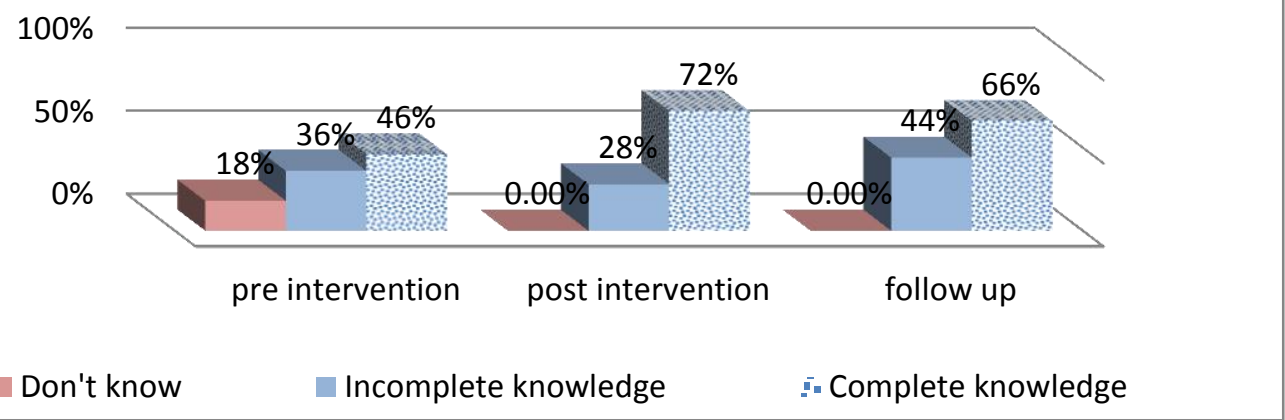

Figure (1): Showed nurses' knowledge about safety medication administration rights on pre, post and follow-up.

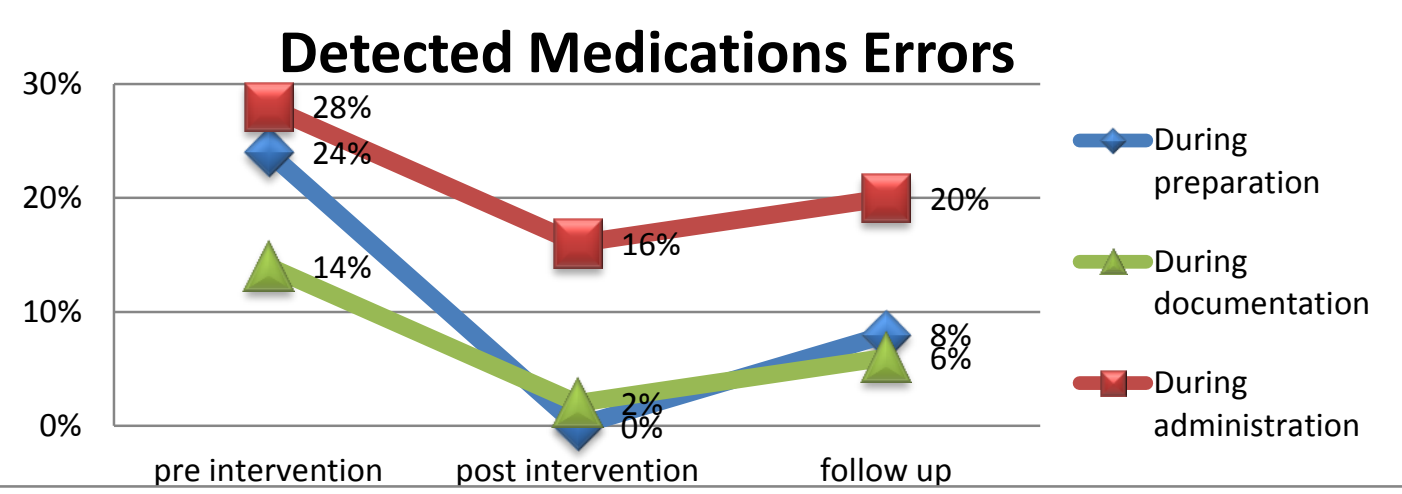

Figure (2): Distribution of nurses according to conducting errors in preparation, administration and documentations of medication on pre, post and follow -up.

Table (2): Mean scores of nurses' total knowledge about medication errors and different medication route on pre, post and follow -up.

\begin{tabular}{|c|c|c|c|c|c|}
\hline \multirow[t]{2}{*}{ Items } & \multicolumn{3}{|c|}{$\begin{array}{c}\text { Mean scores of total nurses' knowledge on pre, } \\
\text { post and follow-up test } \\
(n=50)\end{array}$} & \multirow[t]{2}{*}{ ANOVA test } & \multirow[t]{2}{*}{$p$-value } \\
\hline & Pretest & Posttest & Follow up test & & \\
\hline $\begin{array}{l}\text { Total knowledge score about } \\
\text { medication errors } \\
\text { Range }(0-16) \\
\text { Mean } \pm S D\end{array}$ & $\begin{array}{c}2-15 \\
8.02 \pm 3.7\end{array}$ & $\begin{array}{c}8-16 \\
13.64 \pm 2.09\end{array}$ & $\begin{array}{c}9-15 \\
12.58 \pm 1.6\end{array}$ & $81.65^{(H S)}$ & $<.001$ \\
\hline $\begin{array}{l}\text { Total knowledge score about different } \\
\text { routes of medication administration } \\
\text { Range }(0-29) \\
\text { Mean } \pm S D\end{array}$ & $\begin{array}{c}9-26 \\
16.82 \pm 4.6\end{array}$ & $\begin{array}{c}14-27 \\
23.34 \pm 2.8\end{array}$ & $\begin{array}{c}19-27 \\
23.14 \pm 1.6\end{array}$ & $65.67^{(H S)}$ & $<.001$ \\
\hline $\begin{array}{l}\text { Total knowledge score about child } \\
\text { medication errors and different routes } \\
\text { of medication administration } \\
\text { Range }(0-45) \\
\text { Mean } \pm S D\end{array}$ & $\begin{array}{c}15-40 \\
24.84 \pm 6.7\end{array}$ & $\begin{array}{c}24-42 \\
36.98 \pm 4.2\end{array}$ & $\begin{array}{c}31-40 \\
35.72 \pm 2.00\end{array}$ & $100.28^{(H S)}$ & $<.001$ \\
\hline
\end{tabular}




\section{Children Medication Safety strategies: Its effect on Reducing Medication Errors}

among Pediatric Nurses

Table (3) Means scores of total nurses' practices of safety preparation and administration of medication on pre, post and follow-up.

\begin{tabular}{|c|c|c|c|c|}
\hline \multirow[t]{2}{*}{ Items } & \multicolumn{3}{|c|}{$\begin{array}{l}\text { Means scores of total nurses' practices of safety preparation and } \\
\text { administration of medication on pre, post and follow-up tests } \\
\qquad(n=50)\end{array}$} & \multirow[t]{2}{*}{$\overline{A N O V A}$ test } \\
\hline & Pretest & $\overline{\text { Posttest }}$ & Follow up test & \\
\hline \multicolumn{5}{|l|}{ Total nurse practices } \\
\hline $\begin{array}{c}\text { Range () } \\
\text { Mean } \pm S D\end{array}$ & $\begin{array}{c}12-19 \\
14.84 \pm 1.4\end{array}$ & $\begin{array}{c}12-22 \\
16.80 \pm 1.7\end{array}$ & $\begin{array}{c}13-17 \\
14.82 \pm 0.96\end{array}$ & $34.691^{(H S)}$ \\
\hline
\end{tabular}

Table (4): Total means of medication safety audit on pre, post and follow-up.

\begin{tabular}{||c|l|l|l|l|}
\hline \multirow{2}{*}{ Items } & \multicolumn{2}{|c|}{$\begin{array}{c}\text { Mean scores of total medication safety audit list among } \\
\text { studied nurses on pre, post and follow-up intervention } \\
(\boldsymbol{n}=50)\end{array}$} & \multirow{2}{*}{ ANOVA test } \\
\cline { 2 - 4 } & \hline \multicolumn{2}{|c|}{ Posttest } & Follow up test & \\
\cline { 2 - 4 } $\begin{array}{l}\text { Total medication safety audit } \\
\text { list }\end{array}$ & & & & \\
Range () & $6-8$ & $8-11$ & $6-10$ & \multirow{2}{*}{136.101} \\
Mean $\pm S D$ & $6.64 \pm 0.67$ & $9.1 \pm 0.71$ & $8.1 \pm 0.86$ & \\
\hline
\end{tabular}

Table ( 5 ): Pearson Correlation between total knowledge and total medication observation form

\begin{tabular}{|l|c|c|}
\hline Items & \multicolumn{2}{|c|}{ Total knowledge score } \\
\hline Total medication observation form & $.292^{* *}$ & .000 \\
\hline
\end{tabular}

**. Correlation is significant at the 0.01 level (2-tailed).

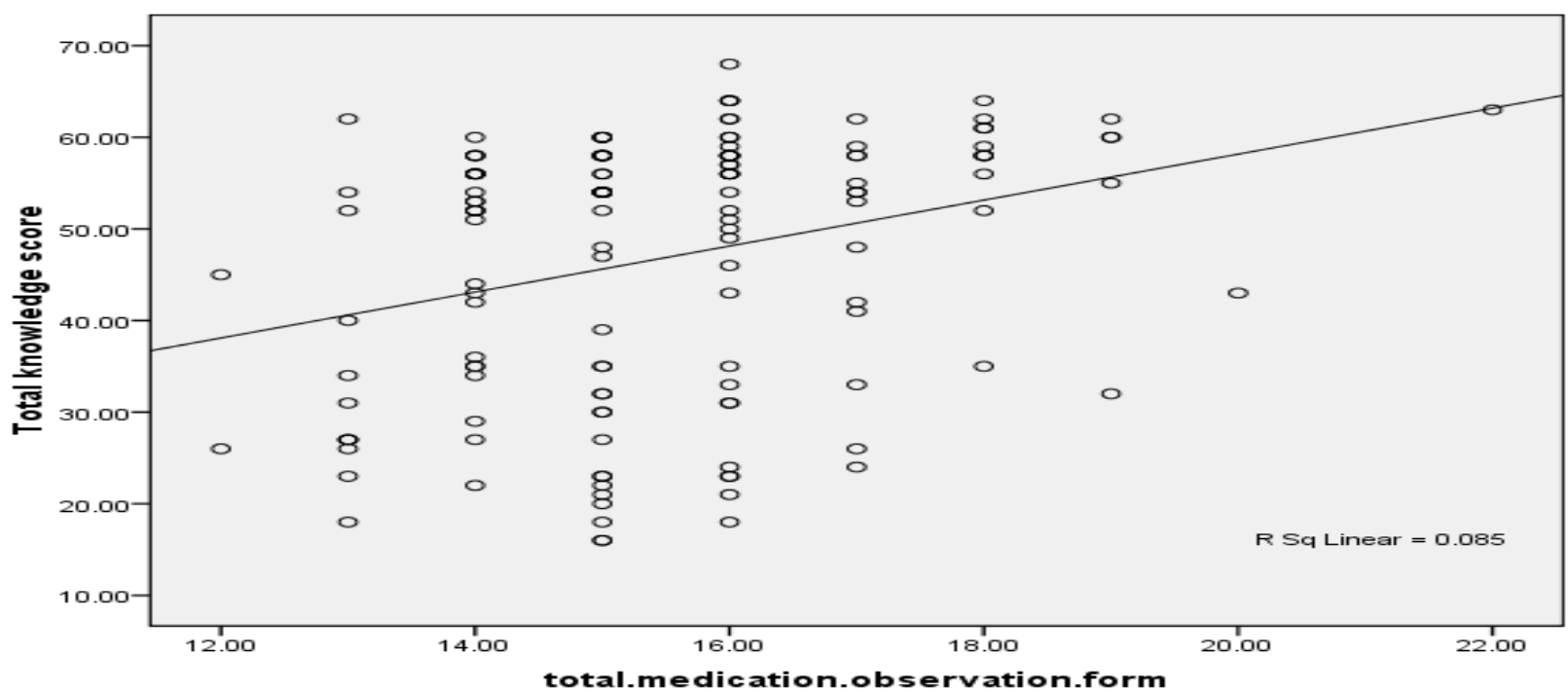

Figure (3) Pearson Correlation between total knowledge and total medication Observation form 


\section{Children Medication Safety strategies: Its effect on Reducing Medication Errors among Pediatric Nurses}

\section{Discussion}

Medication safety is a major concern for pediatric nurses, Administration errors are a leading cause of death (Dedefo, Mitike, \& Angamo , 2016). The child is exposed to at least one medication error per day (Wright, 2012). Pediatric patients were found to be exposed to medication errors three times more than adults and about 39 out of every 100 children suffered from medication error during an emergency (AAP, 2018). Medication errors affects pediatric' safety and results in a large financial burden to the health service. So, great efforts should be directed to hospital units and nursing shifts, on which errors occurred to assist in improving nursing care and ensure children's safety (Mohamed \&Gabr , 2011).

The current study hypothesized that:

"Pediatric nurses who followed children medication safety strategies will have fewer medication errors" The results of the current study support the hypothesis. For this, findings showed that reduced medication errors and improved nurses' knowledge and practices regarding medication administration safety.

Regarding nurses' total knowledge about medication route and medication safety on pre, post and follow-up tests. results showed that nurses had higher scores of correcte knowledge about medication safety on posttest (13.64 \pm 2.09$)$ and follow- up test $(12.58 \pm 1.6)$ than on pretest $(8.02 \pm 3.7)$. This could be inferr that the safety strategies helped nurses to improve their knowledge about medication safety.

Furthermore, nurses showed less medication safety knowledge on follow up test than on posttest. This could be due to the elapse period following the safety strategies and the fact that nurses are exposed to relapse on their previous practice. On the other hand, this reflected that nurses needed continuous education to sustain safety practice.

These results were consistent with Kabeel \& Naglaa (2016). They found that the implementation of clinical guidelines educational program of medication errors improves pediatric nurses' knowledge regarding child safety and errors were decreased. This could be related to the effectiveness of the safety strategies of medication safety, and that the researcher used different educational strategies beside (oral presentations, group discussion, and feedbacks).

These results were consistent with Nair, (2011) .He illustrated that cardiac nurses in the ICU have above average knowledge about pediatric medicine administration safety. Also, these results were agreed with Bülbül et al., (2014) who illustrated that nurses who worked in pediatric wards did not receive a standard education in terms of drug administration and preparation. They also, showed that nurses' knowledge improved with training.

Regarding nurses' practices related to medication preparation and administration for children on pre, post and follow-up tests, the present study illustrated that the level of nurses' performance was significantly improved after implementation of safety strategies on post and follow-up tests than on pretest: the majority of nurses prepared drug and administer it correctly on posttest and follow up tests than on pretest. Therefor medication errors were decreased and children's safety were maintained. This could be attributed to the fact that safety strategies increased nurses' knowledge and 


\section{Children Medication Safety strategies: Its effect on Reducing Medication Errors among Pediatric Nurses}

in turn changed their practices and attitudes to the best. These results were consistent with Murphy \& While (2012). They highlighted that regular training helped pediatric nurses to recognize medication errors, improve their performance regarding drug practices and maintaining medication safety. These findings agreed with Ronda, Fallis, McMillan \& Edward (2009). They reported that the essential component of medication safety process were related to medication administration and monitoring the child by the nurse.

Also. These results were consistent with Ahmed, Barber, Jani, Garfield\& Franklin (2016) who found that implementation of clinical instruction intervention of medication errors was effective in improving children safety and level of nurses' practice. Also, these findings agreed with $\mathrm{Xu}, \mathrm{Li}, \mathrm{Ye} \& \mathrm{Lu}$ (2014) who reported that nurses' awareness and skills of children medication safety were enhanced, and medication errors were reduced after implementation of the intervention. In the same context, these results were consistent with Latimer, Hewitt, Stanbrough, \& McAndre (2017).They reported that educational strategies improved nurses' skills, facilitate the identification of unsafe practices, and allowing errors to be picked up and therefore achieving safety.

Also, these results were consistent with Volpatto , Wegner, Gerhardt\& Pedro (2017) who reported that nurses' performance was improved after the implementation of a computerized physician error system, use of clinical simulation, implementation of dose management protocols and reporting systems so children safety is increased.
Regarding correlation between total medication safet audit list and total medication observation form. This study showed that there were a positive correlation between total medication safety audit list and total medication observation form at $0.001 \%$ level of statistical significance. This reflected the importance of children medication safety strategies in improving nurses knowledge and practices to reduce medication errors.

\section{Conclusion}

Based on the finding of the present study and the research hypotheses, it was concluded that implementation of children medication safety strategies improved nurses' knowledge and practices regarding medication safety on post and follow-up tests than on pretest. Also, it contributed to decrease medication errors on post and follow-up tests than on pretest.

\section{Recommendations}

Based on the findings of the present study, the following recommendations are suggested:

\section{A. Recommendations}

- Medication Safety strategies should be applied at all pediatric units to improve nurses' knowledge and practices regarding medication safety.

- In service training units should be established in each pediatric unites to enhance nurses' practice regarding medication safety.

\section{References}

Ahmed, Z., Barber ,N., Jani ,Y., Garfield, S. \& Franklin B .(2016). Economic Impact of Electronic Prescribing in the Hospital Setting: A Systematic 


\section{Children Medication Safety strategies: Its effect on Reducing Medication Errors among Pediatric Nurses}

Review. International Journal of Medical Informatics, 88, 1-7.

American Academy of Pediatrics (AAP). (2012). Prevention of Medication Errors in the Pediatric Inpatient Setting. Pediatrics, 112:431-36.

American Academy of Pediatrics(2018)s. Pediatric medication safety in the emergency department. Pediatrics, 141(3), e20174066.

Bonney, W. (2013). Medical Errors: Moral and Ethical Considerations. Journal of Hospital Administration, 3(2), 80.

Bülbül, A., Kunt, A., Selalmaz, M., Sözeri, Ş., Uslu, S., \& Nuhoğlu, A. (2014). Assessment of knowledge of Pediatric Nurses Related with Drug Administration and Preparation. Turkish Archives of Pediatrics/Türkish Pediatric Arşivi, 49(4), 333.

Choi, I., Lee, S., Flynn, L., Kim, C., Lee, S., Kim, N., \& Suh, D. (2016). Incidence and Treatment Costs Attributable to Medication Errors in Hospitalized Patients. Research in Social and Administrative Pharmacy, 12(3), 428-437.

Dedefo, M., Mitike, A., \& Angamo, M. (2016). Incidence and Determinants of Medication Errors and Adverse Drug Events Among Hospitalized Children in West Ethiopia. BMC pediatrics, 16(1), 81

El-Shazly, A. N., Al-Azzouny, M. A., Soliman, D. R., Abed, N. T., \& Attia, S. S. (2017). Medical errors in neonatal intensive care unit at Benha University Hospital, Egypt. Eastern Mediterranean Health Journal, 23(1).

Joint Commission on Accreditation of Healthcare Organizations.
(2002)Hospital Accreditation

Standards. Oakbrook Terrace, IL:

Joint Commission on Accreditation of Healthcare Organizations;

Haelle, T., \& Willingham, E. (2016). The Informed Parent: A Science-based Resource for Your Child's First Four Years. TarcherPerigee

Härkänen, M., Turunen, H., Saano, S., \& Vehviläinen-Julkunen, K. (2013). Medication errors: what hospital reports reveal about staff views. Nursing Management, 19(10).

https://www.ncbi.nlm.nih.gov

Kabeel, A.,Naglaa, F. (2016) .Effect of Educational Clinical Guidelines Program of Medication Errors on Pediatric Nurses' Knowledge Regarding Patient Safety .Journal of Nursing and Health Science: 2320 1959.p- ISSN: 2320-1940 Volume 5, Issue 6 Ver. pp. 98-106,.Available at : www.iosrjournals.org.

Latimer, S., Hewitt, J., Stanbrough, R., \& McAndrew, R. (2017). Reducing medication errors: Teaching strategies that increase nursing students' awareness of medication errors and their prevention.

Ministry of health Singapore (2009)medication safety audite list for nurses. https://www.moh.gov.sg/docs/libra $\underline{\text { riesprovider }}$

Mohamed, N., \& Gabr, H. (2011). Quality Improvement Techniques to Control Medication Errors in Surgical Intensive Care Units at Emergency Hospital. Journal of Medicine \& Biomedical Sciences, (2).

Mohammad, I., Hojjati, H., Sharifniya, S. H., \& Ehsani, S. R. (2012). Evaluation of Medication Error in Nursing Students in Four 


\section{Children Medication Safety strategies: Its effect on Reducing Medication \\ Errors among Pediatric Nurses}

Educational Hospitals in Tehran. Iranian Journal of Medical Ethics and History of Medicine, 3(1), 60-69

Mrayyan, M. T. (2012). Reported Incidence, Causes, and Reporting of Medication Errors in Teaching Hospitals in Jordan: A Comparative Study. Contemporary Nurse, 41(2), 216-232.

Murphy, M., \& While, A. (2012). Medication Administration Practices A mong Children's Nurses: A Survey. British Journal of Nursing, 21(15), 928-933.

Murray, P., Wolcott, J., Bootman, J., \& Cronenwett, L. (2010). Preventing Medication Errors, 409 (46). Washington, DC: National Academies Press

Nair, V. S. (2011). A study to assess the knowledge about the pediatric medicine administration in congenital heart intensive care unit. Available at: http://dspace.sctimst.ac.in/ispui/bit stream.

National Coordinating Council for Medication Errors Reporting and Prevention: NCCMERP.( 2015). Medication Safety Alert! Nurse Advise-ERR [Newsletter]. Available at :www.ismp.org.

RayhanA.Tariq\&Yevgeniya,S.(2018)Medi cation Errors. StatPearls Publishing,

Ronda, S., Fallis, W., McMillan, D., \& Edwards, M. (2011). Napping during night shift: practices, preferences, and perceptions of critical care and emergency department nurses. Critical care nurse, 31(2), e1-e11.
Schmidt, C., \& Bottoni, T. (2013). Improving Medication Safety and Patient Care in the Emergency Department. Journal of Emergency Nursing, 29(1), 12-16.

Stockwell DC, Landrigan CP, Toomey SL, et al.( 2018 ) Adverse events in hospitalized patients. Pediatrics ;142(2).

Vickerie,S.(2017).Strategies-for-

Preventing-Medication

Errors.Available

at : https://minoritynurse.com

Volpatto, B., Wegner, W., Gerhardt, L., \& Pedro, E. (2017). Medication Errors in Pediatric and Preventive Strategies: An Integrative Review. Cogitare Enferm, 22(1), e45132.

World Health Organisation. (2016).Reporting and Learning Systems for Medication Errors: The Role of Pharmacovigilance Centres 1st ed. Available at: https://scholar.google.com.eg/schol ar.

World Health Organization (2017). Promoting Safety of Medicines for Children .ISBN 978-92-4-156343-7 , NLM Classification: WS : 366

Wright,G.,(2012).Better Environments for Nurses Mean Fewer Medication Errors: Robert Wood Johnson Foundation . Available at: http://www.rwjf.org/facebook

Xu, C., Li, G., Ye, N., \& Lu, Y. (2014). An Intervention to Improve Inpatient Medication Management: A Before and After Study. Journal of Nursing Management, 22(3), 286-294. 